\title{
Parque Nacional Chapada dos Veadeiros e as características socioeconômicas dos municípios limítrofes
}

\section{Socio-economic characteristics of the cities near Chapada dos Veadeiros National Park}

\author{
Amanda Barbosa Rêgo ${ }^{1}$ \\ Joana D'Arc Bardella Castro \\ Talita Freitas Souza Barros ${ }^{3}$
}

\section{RESUMO}

O cerrado é um relevante bioma nacional, sendo considerada a Savana mais rica do mundo quanto à biodiversidade. Em contraposição à sua importância ambiental, ele sofre grande degradação humana motivada, primordialmente, pela exploração agropecuária. A Unidade de Conservação Permanente (UC) de maior relevância no cerrado é o Parque Nacional Chapada dos Veadeiros (PNCV), que se localiza nas cidades goianas de Alto Paraíso de Goiás, Cavalcante, Nova Roma, Teresina de Goiás e São João da Aliança. O objetivo do estudo foi analisar os impactos socioeconômicos do PNCV sobre as comunidades residentes nestes municípios. Realizou-se pesquisa bibliográfica acerca das UC, do PNCV e histórico das cidades em que se situa. Dados estatísticos do Instituto Brasileiro de Geografia e Estatística (IBGE) foram utilizados para características sociais e econômicas dos municípios pesquisados. Percebeu-se que as cidades goianas que comportam a PNCV são pequenas, com alta porcentagem de pessoas em nível de pobreza e Índice de Desenvolvimento Humano medianos, com exceção de Alto Paraíso. Há grande potencial para a exploração econômica sustentável dessa área de preservação ambiental, o que pode permitir o crescimento e desenvolvimento da comunidade inserida em seu território.

PALAVRAS-CHAVES: Cerrado. Unidades de Conservação Ambiental. Parque Nacional Chapada dos Veadeiros.

\begin{abstract}
Cerrado is a relevant national biome, and in terms of biodiversity, it is considered the richest savanna in the world. Notwithstanding its environmental importance, Cerrado suffers a human degradation motivated primarily by agricultural exploitation. The most relevant Permanent Conservation Unit (CU) in cerrado is Chapada dos Veadeiros National Park (CVNP), located in the cities of Alto Paraíso de Goiás, Cavalcante, Nova Roma, Teresina de Goiás and São João da Aliança. The study's objective was to
\end{abstract}

\footnotetext{
${ }^{1}$ Possui graduação em Direito pela Universidade Federal de Uberlândia e Pós Graduação em Direito Tributário pelo Instituto Brasileiro de Estudos Tributários. Atualmente é Servidora Pública no Tribunal de Justiça do Estado de Goiás e está cursando Ciências Econômicas na Universidade Estadual de Goiás. E-mail: amandabrego@hotmail.com

${ }^{2}$ Possui graduação em Ciência Econômicas pela Universidade Estadual de Goiás (1983) e Mestrado em Economia de Empresas pela Universidade Católica de Brasília (2003). Doutorado em Economia pela UnB. Pós-doutorado na UnB. Atualmente é professora titular da Universidade Estadual de Goiás.Docente do programa Stricto Sensu Recursos Naturais do Cerrado- RENAC. E-mail : joanabardella@brturbo.com.br

${ }^{3}$ Mestranda na Universidade Estadual de Goiás - no Programa de Pós-Graduação Stricto Sensu em Recursos Naturais do Cerrado (RENAC), Bolsista da Coordenação de Aperfeiçoamento de Pessoal de Nível Superior (CAPES) em parceria com a Fundação de Amparo à Pesquisa do Estado de Goiás (FAPEG), cursando Ciências Econômicas pela Universidade Estadual de Goiás - Campus de Ciências Socioeconômicas e Humanas. E-mail : economia.talita@gmail.com
} 
analyze the socio-economic impacts of the CVNP on its residing communities. We did bibliographical research about the CU, the CVNP and the cities' history where it is located. Statistic data from the Brazilian Institute of Geography and Statistics (IBGE) were used to understand the social and economic characteristics of the surveyed municipalities. We verified that the cities where the CVNP is located are small, have a high percentage of people in poverty conditions and have an average Human Development Index, except for Alto Paraíso. There is a great potential for sustainable economic exploitation in this area, which may allow the growth and development of the communities within its territory.

KEYWORDS: Cerrado. Environmental Conservation Units. National Park Chapada dos Veadeiros.

JEL: Q20; Q56; Q57

\section{INTRODUÇÃO}

De acordo com o Ministério do Meio Ambiente (MMA), o Cerrado é o segundo maior bioma da América do Sul, ocupando $22 \%$ do território nacional. Além disso, as nascentes das três maiores bacias hidrográficas da América Latina, Amazônica/Tocantins, São Francisco e Prata, localizam-se nesse ecossistema, o que favorece sua biodiversidade, e por isso é conhecida como a savana mais rica do mundo (BRASIL, 2018).

Apesar de sua importância, atrás somente da Mata Atlântica, o cerrado é o bioma brasileiro que mais sofre com a ocupação humana, ocasionada principalmente pela intensa exploração agropecuária existente ao longo de sua extensão. Há ainda o agravamento da degradação pelo fato de ser uma vegetação desprotegida, pois somente $8,21 \%$ de sua extensão é legalmente constituída como unidade de conservação ambiental (UC) (BRASIL, 2018).

O Parque Nacional da Chapada dos Veadeiros (PNCV) é a principal UC do Cerrado. Em 2017, por meio do Decreto Federal não numerado de 05 de junho de 2017, teve sua dimensão aumentada em aproximadamente quatro vezes, contando, atualmente, com a extensão de 240.000 hectares. Localiza-se no nordeste goiano, nas cidades de Alto Paraíso de Goiás, Cavalcante, Nova Roma, Teresina de Goiás e São João da Aliança. É reconhecido nacionalmente e internacionalmente como um bioma com fauna e flora extremamente ricas, tanto que em 2001 foi considerado pela Organização das Nações Unidas para a Educação e Cultura (UNESCO) um Patrimônio Natural Mundial (UNESCO, 2017).

Mesmo que o PNCV se estenda pelo território dos municípios acima descritos, a cidade que em primeiro momento mais se beneficiou com o turismo gerado pela sua criação foi Alto Paraiso, que é considerada um santuário do misticismo, do espiritualismo e das terapias naturais (GOIÁS, 2013a).

Os demais municípios possuem menores índices de desenvolvimento humano municipal (IDHM), exploram precipuamente atividades agropecuárias, e o ecoturismo surgiu como atividade econômica em épocas mais recentes, com pouca organização e concentração (GOIÁS, 2013a).

Ao ser instituída uma UC com proteção integral, que é o caso do PNCV, algumas restrições à exploração da terra são impostas por legislação federal e estadual. Essa regulamentação afeta diretamente os municípios que são considerados pobres, o que gerou e gerará consequências sociais e econômicas para essas regiões. 
Diante deste dilema em conciliar proteção ambiental e desenvolvimento foi proposto este estudo com o objetivo de analisar os impactos socioeconômicos do PNCV sobre as comunidades residentes nos municípios. Para tanto, foi feita descrição sobre Unidades de Conservação, em especial sobre Parques Nacionais; e detalhouse sobre os índices socioeconômicos de cada município limítrofe ao Parque Nacional Chapada dos Veadeiros.

\section{AS UNIDADES DE CONSERVAÇÃO E OS PARQUES NACIONAIS}

O conceito de área de proteção ambiental nasceu no século XIX, quando se iniciou a conscientização do potencial destrutivo da indústria moderna ao patrimônio natural. Após a segunda guerra mundial, a discussão passou a existir em âmbito internacional. Em 1948 foi fundada a "União Mundial pela Conservação da Natureza", uma organização não governamental, formada por mais de 1200 organizações de 91 Estados e 127 agências governamentais de 160 Estados. Com a percepção gradual da alta degradação, houve uma difusão mundial de valores ambientais que culminaram na elaboração de um Tratado Internacional das Nações Unidas em 1992 (BASSI, 2016).

A Constituição Federal Brasileira de 1988 trouxe em seu texto diversas normas que visam proteger e garantir um meio ambiente saudável à sua população. Dentre as disposições que tratam do tema, podemos ressaltar seu art. $225, \S 1^{\circ}$, III, o qual apregoa que:

Art. 225. Todos têm direito ao meio ambiente ecologicamente equilibrado, bem de uso comum do povo e essencial à sadia qualidade de vida, impondose ao Poder Público e à coletividade o dever de defendê-lo e preservá-lo para as presentes e futuras gerações.

$\S 1^{\circ}$ Para assegurar a efetividade desse direito, incumbe ao Poder Público: III - definir, em todas as unidades da Federação, espaços territoriais e seus componentes a serem especialmente protegidos, sendo a alteração e a supressão permitidas somente através de lei, vedada qualquer utilização que comprometa a integridade dos atributos que justifiquem sua proteção (BRASIL, 1988, p.77).

Com o objetivo de regulamentar este artigo, foi promulgada a Lei 9.985/2000 que instituiu o Sistema Nacional de Unidades de Conservação (SNUC). Esta norma traz em seu art. $2^{\circ}$ a conceituação legal do que seria uma UC:

Espaço territorial e seus recursos ambientais, incluindo as águas jurisdicionais, com características naturais relevantes, legalmente instituído pelo Poder Público, com objetivos de conservação e limites definidos, sob regime especial de administração, ao qual se aplicam garantias adequadas de proteção (BRASIL, 2000, p.01).

As UC podem ser de dois tipos; de Proteção Integral e de Proteção Sustentável ${ }^{4}$. As primeiras possuem como objetivo primordial a preservação da natureza, não se permitindo a intervenção humana, exceto para a manutenção dos processos ecológicos ou pesquisas científicas. Interessante ressaltar que, para efeitos legais, este tipo de UC é considerada zona rural, incluindo a sua zona de

\footnotetext{
${ }^{4}$ As Unidades de Uso Sustentável têm como escopo principal harmonizar a proteção da biodiversidade e da natureza com o uso sustentável de parte de seus recursos naturais pelas populações residentes (OLIVEIRA, 2017).
} 
amortecimento. Dentre as UC de proteção integral encontramos os Parques Nacionais, cuja posse e domínio são públicos (OLIVEIRA, 2017).

Os Parques Nacionais, segundo o art. 11 da Lei 9.985/2000, possuem como finalidade basilar a "preservação de ecossistemas naturais de grande relevância ecológica e beleza cênica, possibilitando a realização de pesquisas científicas e o desenvolvimento de atividades de educação e interpretação ambiental, de recreação em contato com a natureza e de turismo ecológico" (BRASIL, 2000, p.05). É nessa categoria ambiental, criada pela legislação brasileira, que se encontra o nosso objeto de estudo, o Parque Nacional Chapada dos Veadeiros.

O I relatório sobre a área de proteção ambiental alpina italiana ( ${ }^{\circ}$ Report della Rete SAPA) ensina que as áreas de proteção ambiental possuem três funções principais: i) Planejamento Territorial: permitem uma integração das funções ecossistêmicas, conectividades ecológicas e biodiversidade; ii) Economia Verde: conseguem gerar o desenvolvimento econômico, social e cultural da população local; iii) Mudanças Climáticas: limitam os efeitos negativos das alterações climáticas da região (AMATO, et al, 2017).

Para que as funções acima expostas sejam alcanças, o art. 27 da Lei 9985/00 estabelece a necessidade de criação de um plano de manejo, que "deverá abranger a área da Unidade de Conservação, sua zona de amortecimento e os corredores ecológicos, a partir de medidas com a finalidade de promover sua integração à vida econômica social das comunidades vizinhas", O plano de manejo do PNCV foi editado em 2009, pelo Ministério do Meio Ambiente, por meio do Instituto Chico Mendes de Preservação da Biodiversidade (ICMBio).

\section{MÉTODO DA PESQUISA}

O método da pesquisa é o bibliográfico e documental. As análises foram subsidiadas pelas discussões teórico-metodológicas encontradas em livros e artigos científicos nacionais e internacionais, preferencialmente publicados nos últimos cinco anos.

As cidades incluídas na investigação foram Alto Paraíso de Goiás, Cavalcante, Nova Roma, Teresina de Goiás e São João da Aliança.

O estudo buscou dados no Instituto Brasileiro de Geografia e Estatística (IBGE); no Instituto Mauro Borges (IMB) e no Atlas do Desenvolvimento Humano do Brasil, realizado pelo Programa das Nações Unidas para o Desenvolvimento (PNUD), Instituto de Pesquisa Econômica e Aplicada (IPEA) e Fundação João Pinheiro.

Os Índices que foram retirados de Dados do IBGE e do Atlas do Desenvolvimento Humano do Brasil foram: Renda Per Capita; Índice de Gini; Porcentagem de Pobres; Índice de Desenvolvimento Humano Municipal (IDHM); Mortalidade Infantil e Expectativas de Anos de Estudo. Os índices encontrados para as cidades pesquisadas foram comparados com os índices do Estado de Goiás e do Brasil.

As instituições acima processaram dados que foram extraídos através dos Censos Demográficos de 1991, 2000 e 2010. As tabelas elaboradas, dos índices acima expostos, utilizam este espaço temporal como recorte.

Para calcular a Renda per capita faz-se o somatório dos rendimentos de todos os indivíduos residentes no local de referência, no mês anterior à data do Censo, e dividiu-se pela quantidade de indivíduos residentes neste local. Este indicador tem como objetivo explicitar a capacidade média de aquisição de bens e serviços pela população de determinada localidade (PNUD, et al., 2013) 
O índice de Gini é aplicado para medir a concentração econômica de determinado grupo de pessoas. Seu valor varia de 0 a 1 , de forma que no 0 temos uma economia sem qualquer desigualdade social entre a população e no 1 , todo 0 patrimônio se concentra na mão de uma pessoa (WOLFFENBÜTTEL, 2004).

A porcentagem de pobres mostra a proporção de pessoas que possuem renda domiciliar per capita inferior a $\mathrm{R} \$ 140,00$ (cento e quarenta reais) mensais (PNUD, et. al., 2013).

Os dados do IDHM têm foco no desenvolvimento das pessoas, e não somente no desenvolvimento econômico. Seu objetivo é trazer informações que possam nortear políticas públicas que visem à qualidade de vida da população. Para a realização de seus cálculos são observados os componentes longevidade, educação e renda. Valores abaixo de 0,550 demostram baixo desenvolvimento humano; entre 0,550 e 0,699 é médio; entre 0,700 e 0,799 é alto, e acima de 0,800 é considerado muito alto. O IDHM do Brasil é 0,727 (PNUD, et. al., 2013).

A mortalidade infantil traduz a quantidade de crianças que morreram com menos de 01 ano de idade a cada mil nascidos vivos. A expectativa de anos de estudo, indica quantos anos uma criança que inicia sua vida escolar no ano de referência, completará de estudo ao atingir a idade de 18 anos (PNUD, et. al., 2013).

No Estado de Goiás houve a criação do Índice de Desempenho dos Municípios Goianos (IDM), que visa diagnosticar e comparar o desempenho dos municípios do Estado, a fim de que a gestão governamental seja avaliada ao longo do tempo e políticas públicas tenham dados que permitam o seu planejamento. A pontuação atribuída varia em uma escala de 0 a 10, na qual 10 representa o melhor nível de desempenho e 0, o pior nível de desempenho (GOIÁS, 2019).

O IDM é calculado com base em 34 variáveis, divididas em 6 dimensões: economia, trabalho, educação, infraestrutura, segurança e saúde. Entende-se importante trazer os dados do IDM relativos às cidades estudadas, em contraponto à cidade que conseguiu o maior (Ouvidor) e o pior (Baliza) desempenho em 2018, pois é possível ver o retrato de desenvolvimento dos municípios estudados após o Censo 2010 (GOIÁS, 2019).

A coleta de dados deste índice elaborado pelo Estado de Goiás ocorre bienalmente, e teve início no ano 2010. Assim, para a elaboração dos gráficos que compilam estas informações, foi utilizado como lapso temporal os anos de 2010, 2012, 2016 e 2018. Não houve publicação do relatório referente ao ano de 2014 no site oficial do IMB, por isso sua ausência nas análises.

\section{RESULTADOS E DISCUSSÕES}

\section{Histórico do PNCV}

Pinturas rupestres indicam que a região da Chapada dos Veadeiros teve seus primeiros sinais de habitação há 10.000 anos. Como o local é de difícil acesso, vários grupos indígenas, principalmente os Crixás e os Canoeiros, e quilombolas se refugiaram na região no século XVIII, com o intuito de se instalarem em local seguro. No entanto, em 1737 iniciou-se a extração das minas de ouro localizadas em Cavalcante e, posteriormente, houve exploração da agricultura do trigo e caça ao veado campeiro na região (LIMA, 2013).

As incursões ao Planalto Central, com o objetivo de fixar a nova capital brasileira, fizeram com que Coimbra Bueno, em 1960, escrevesse uma carta para o então presidente Juscelino Kubistchek, solicitando a criação de um Parque na região, 
a fim de que as belezas do cerrado fossem preservadas. Desta forma, em 1961 foi editado o Decreto 49.875 criando o Parque do Tocantins, com área de 625.000 hectares (LIMA, 2013).

Diante das pressões dos proprietários de terras e produtores agrícolas, por 30 anos, a extensão do PNCV (esse nome foi estabelecido em 1972, pelo Decreto 70.492) foi paulatinamente diminuída, tanto que em 1990 chegou ao tamanho de 65.514 hectares (LIMA, 2013).

Entretanto, em setembro de 2001, o presidente Cardoso (1995-2003) editou Decreto $\mathrm{s} / \mathrm{n}^{\circ}$ que quase quadruplicou a área do Parque, elevando sua extensão para 230.000 hectares (LIMA, 2013). Tal decreto foi considerado nulo pelo Supremo Tribunal Federal em agosto de 2003, mediante o Mandado de Segurança 24184. Recentemente, em 5 de junho de 2017, o Presidente Temer (2016-2019) editou novo Decreto s/no ampliando a extensão do PNCV para 240.611 hectares.

De acordo com Silva et al. (2018), a área de influência do PNCV se estende por $15.379,9 \mathrm{Km}^{2}$ e, além do Parque, existem outras unidades nesta região que possuem grande relevância ecológica, social e cultural. No local encontra-se: o maior território quilombola do Brasil, o dos Kalunga; a terra indígena dos Avá-Canoeiros; a Área de Proteção Ambiental do Pouso Alto, uma UC a nível estadual; 14 projetos de assentamentos rurais do INCRA e 21 Reservas Particulares do Patrimônio Natural.

A procura por alternativas de desenvolvimento econômico sustentável para regiões que comportam UC é sempre um desafio, pois geralmente as UC são vistas pela sociedade e pelo Poder Público como áreas perdidas. Segundo o Plano de Manejo do PNCV (ICMBio, 2009), a maioria da população que vive na região acredita que a implementação da Área de Proteção Ambiental (APA) gerará e potencializará iniciativas que unirão o desenvolvimento econômico, a conservação da natureza e a preservação da história e cultura local.

Ainda neste documento do Ministério do Meio Ambiente- MMA são descritas as principais atividades econômicas que podem ser exploradas pelos citadinos, com baixo impacto ambiental, quer sejam: ecoturismo; turismo histórico-cultural; turismo rural; esportes de aventura e esportes na natureza; pesca esportiva e criação de peixes; tratamentos alternativos e atividades espiritualistas; culinária; manipulação de ervas; apicultura; artesanato; promoção de eventos e cursos e agricultura orgânica (ICMBio, 2009).

\section{Caracterização das cidades cingidas pelo PNCV}

Atualmente o PNCV faz limite com as cidades de Alto Paraíso de Goiás, Cavalcante, Nova Roma, Teresina de Goiás e São João d’Aliança.

Alto Paraíso é a principal cidade da Chapada dos Veadeiros, em decorrência de uma série de características: o distrito de São Jorge é a porta de entrada para o PNCV; está a uma altitude de $1.200 \mathrm{~m}$, localizada sobre o que é considerado o maior bloco de cristal do planeta; localiza-se no mesmo paralelo de Machu Picchu, no Peru. Com isso, se torna um local com grandes atrativos ecológicos, místicos, religiosos e ufológicos (GOIÁS, 2013).

A primeira alusão cartográfica ao local ocorreu em 1836, em que foi chamada de Veadeiros em decorrência da caça aos veados que ocorria em seu território. Foi distrito de Cavalcante até 1953 e somente em 1963 passa a se denominar Alto Paraíso. Em 1950 instala-se a fazenda escola Bona Espera, baseada no esperantismo; e em 1960 foi fundada outra fazenda escola, a Cidade da Fraternidade, baseada no kardecismo. Tais inciativas consagram a região para o movimento 
esotérico e espiritual, tanto que na década de 1980 propôs-se a criação, na cidade, de uma vida em comunidade alternativa, o que gerou para o local, alto movimento migratório (ICMBio, 2009).

Segundo dados do IBGE, sua população estimada em 2018 foi de 7.558 habitantes. Os dados do censo 2010 mostram que a renda média da população do município é de 1,7 salários mínimos; seu Produto Interno Bruto (PIB) per capita é de $\mathrm{R} \$ 18.760,39$, influenciado pelo setor de serviços. O tempo médio de estudo de sua população é de 9,56 anos (09 anos, seis meses e 21 dias) e a mortalidade infantil é de 14,3 óbitos por mil nascimentos. O índice de Gini é de 0,65 e o IDHM é 0,713 (alto) (IBGE, 2017; PNUD, et. al., 2013).

A cidade de Cavalcante teve seu início de povoamento em 1736, em decorrência da descoberta de uma imensa mina de ouro de grande profundidade no córrego Lava Pés. Após o declínio desta exploração, tornou-se grande produtora de trigo, tanto que por muitos anos foi a maior exportadora deste produto para os EUA (CAVALCANTE, 2018). Além das riquezas ecológicas, a cidade conta com rico patrimônio cultural, pois nela habita a população quilombola Kalunga (GOIÁS, 2013a).

O Município tem população estimada de 9.693 pessoas. A renda média municipal é de 2,1 salários mínimos e seu PIB per capita é de $R \$ 25.632,28$, formado principalmente pela indústria local. A mortalidade infantil do município é de 15,4 óbitos a cada mil nascimentos e a expectativa de estudo são de 8,14 anos (8 anos, 1 mês e 20 dias). Seu IDHM é de 0,584 (médio) e o índice de Gini é 0,62 (IBGE, 2017; PNUD, et. al., 2013).

Teresina de Goiás é um município jovem, seu território começou a ser habitado somente em 1960, como um loteamento da cidade de Cavalcante. Em 1968 foi considerado Distrito e se emancipou em 1988 (GOIÁS, 2013a). É conhecida como a capital do Caju em Goiás, possui 17 cachoeiras e comunidades quilombolas (CONHEÇA, 2018). Em 2018, a estimativa populacional era de 3.416 , a renda média dos trabalhadores de 1,6 salários mínimos e seu PIB per capita de $\mathrm{R} \$ 8.653,41$ (um dos mais baixos do Estado de Goiás), formado principalmente pelo setor de serviços. A mortalidade infantil é de 14,6 óbitos a cada mil nascimentos e a expectativa de tempo de estudo de sua população são de 9,78 anos (9 anos, 9 meses e 10 dias). Seu IDHM é 0,661 (médio) e o Índice de Gini é 0,52 (IBGE, 2017; PNUD et. al., 2013).

Cavalcante e Teresina de Goiás possuem estigma de serem pobres. O fato de o PIB de Cavalcante ser alto deve-se a condição de esse município receber Royalties da Usina Serra da Mesa, embora tal condição não gere consequências sociais, tanto que a cidade possui baixo IDHM e alta porcentagem de pobres, como é possível perceber nos gráficos 03 e 04 (SILVA et al, 2018).

O local onde se encontra a cidade de Nova Roma foi habitado desde o séc. XVIII, em decorrência da descoberta de ouro e de outros minérios na região. Por longo período foi distrito de Cavalcante, se tornando município autônomo somente em 1959 (NOVA ROMA, 2018). Possui população estimada de 7.558 pessoas em 2018, com renda mensal dos trabalhadores de 1,7 salários mínimos e PIB per capita de $\mathrm{R} \$ 18.760,39$, oriundo principalmente da exploração agropecuária. A mortalidade infantil do município é 15 óbitos a cada mil nascimentos e a média de estudo populacional é 8,5 anos. O IDMH é 0,634 (médio) e seu índice de Gini é 0,44 (IBGE, 2017; PNUD et.al., 2013).

São João d'Aliança começou a ser habitada em 1910. No início era chamada de Olhos D'água pela quantidade de nascentes que existia em sua região. Tornou-se uma vila com seu atual nome em 1931, mas em 1939 foi extinta, tornando-se um distrito de Formosa; voltou a ser município somente em 1954 (SÃO JOÃO D’ALINÇA, 
2018). No local há uma transição entre a vegetação do cerrado e as florestas úmidas da pré-Amazônia. Por ser banhada por afluentes do Rio Tocantins, possui diversas cachoeiras e corredeiras que permitem a prática de esportes radicais e ecoturismo (GOIÁS, 2013a).

A estimativa em 2018 foi de uma população com 10.257 pessoas, os trabalhadores receberam em média 1,9 salários mínimos e seu PIB per capita foi de $R \$ 19.019,25$, impulsionado pela exploração agropecuária. A mortalidade infantil em 2010 foi de 15,0 óbitos a cada mil nascimentos e o tempo médio de estudo de sua população é estimado em 9,23 anos (9 anos, 2 meses e 22 dias). Seu IDHM foi de 0,685 (médio) e o Índice de Gini 0,53 (IBGE, 2017; PNUD et.al., 2013).

De todas as cidades que compõem o PNCV, São João D'Aliança é o único que possui área de cobertura natural menor que área de cobertura antrópica. Em $2000 \mathrm{a}$ área antrópica correspondia a 67\% da área de Município, já em 2015 atingiu-se os $75 \%$, o que mostra uma alta perda de vegetação natural no local (SILVA et al, 2018).

No ano de 1991 percebe-se que a renda per capta dos habitantes dos municípios de abrangência do PNCV encontrava-se com valores inferiores a $R \$ 300,00$, enquanto o Estado de Goiás e o Brasil alcançavam $R \$ 400,00$ reais ou mais por pessoa. No ano 2000 houve um crescimento significativo nos municípios de Alto Paraíso, São João D'Aliança e no Estado de Goiás, que mesmo com esse crescimento ficaram aquém do rendimento médio alcançado pelo Brasil, o qual registrou o valor de $\mathrm{R} \$ 592,46$ por pessoa. No ano 2010 os resultados são animadores para o município de Alto Paraíso, para o Estado de Goiás e para o Brasil. No entanto, os municípios de Cavalcante, Nova Roma, São João D’Aliança e Teresina de Goiás apresentaram descompasso com o avanço desta década e mantiveram sua renda per capta estagnada em $R \$ 300,00$, resultado semelhante ao do ano de 1991 (Gráfico 1)

Gráfico 1- Renda Per Capita de Alto Paraíso, Cavalcante, Nova Roma, São João D’Aliança, Teresina de Goiás, Goiás e Brasil - 1991-2010

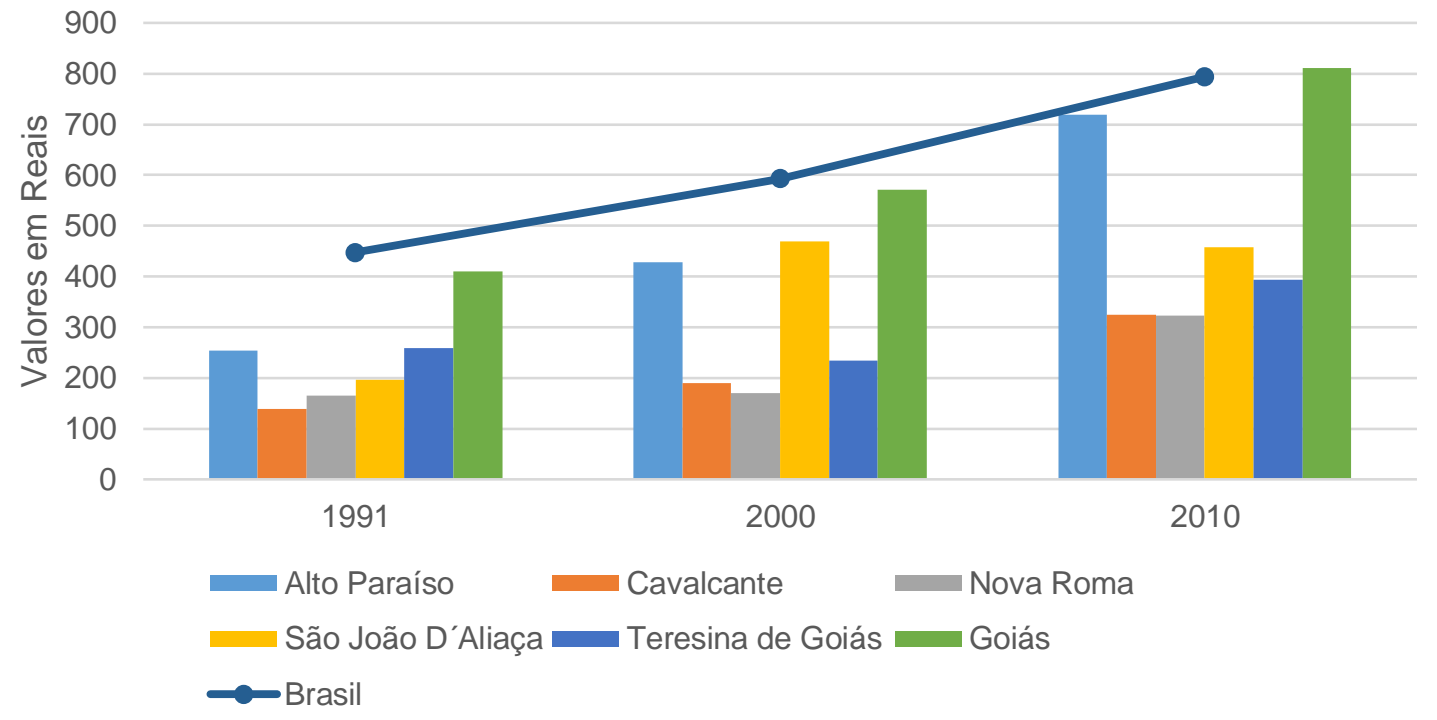

Fonte: Atlas Brasil, PNUD, et. al., 2013. Elaborado pelas autoras.

O índice de Gini manteve-se sem grandes alterações desde o ano de 1991 até o ano de 2010, tanto nos municípios compreendidos no PNCV, quanto no Estado de Goiás e no Brasil. Esse resultado demonstra a necessidade de avanços para uma melhor distribuição de renda (Gráfico 2). 
Gráfico 2- Índice de Gini de Alto Paraíso, Cavalcante, Nova Roma, São João D’Aliança, Teresina de Goiás, Goiás e Brasil - 1991-2010

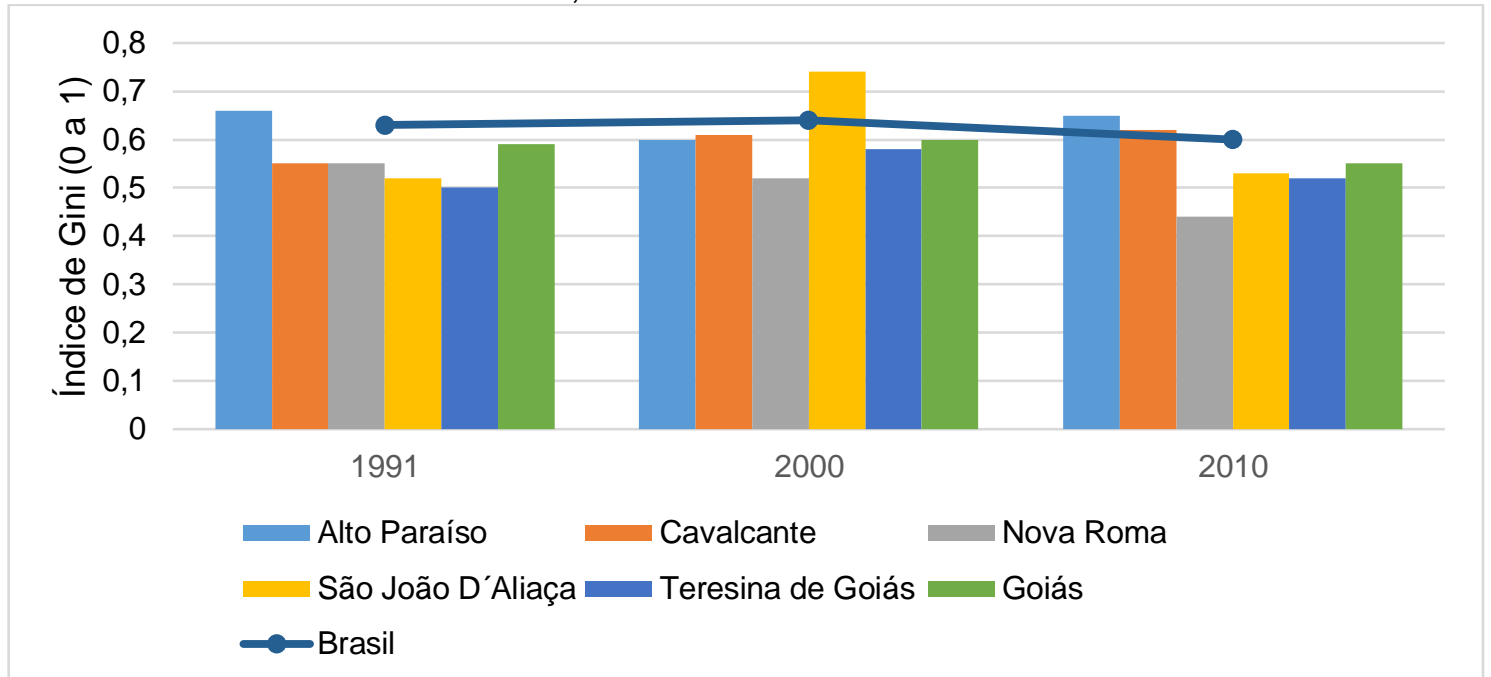

Fonte: Atlas Brasil, PNUD, et al., 2013. Elaborado pelas autoras.

Mesmo com o índice de Gini praticamente estável ao longo do período analisado, observa-se que a porcentagem de pessoas classificadas como pobres declinou significativamente em todos os municípios abarcados pelo PNCV, no Estado de Goiás e no Brasil. Estes gráficos nos chamam atenção para os municípios de Cavalcante e Teresina de Goiás que mantiveram altos os índices de pobreza em dissonância com os demais analisados (Gráfico 3).

Gráfico 3- Porcentagem de Pobres de Alto Paraíso, Cavalcante, Nova Roma, São João D’Aliança, Teresina de Goiás, Goiás e Brasil - 1991-2010

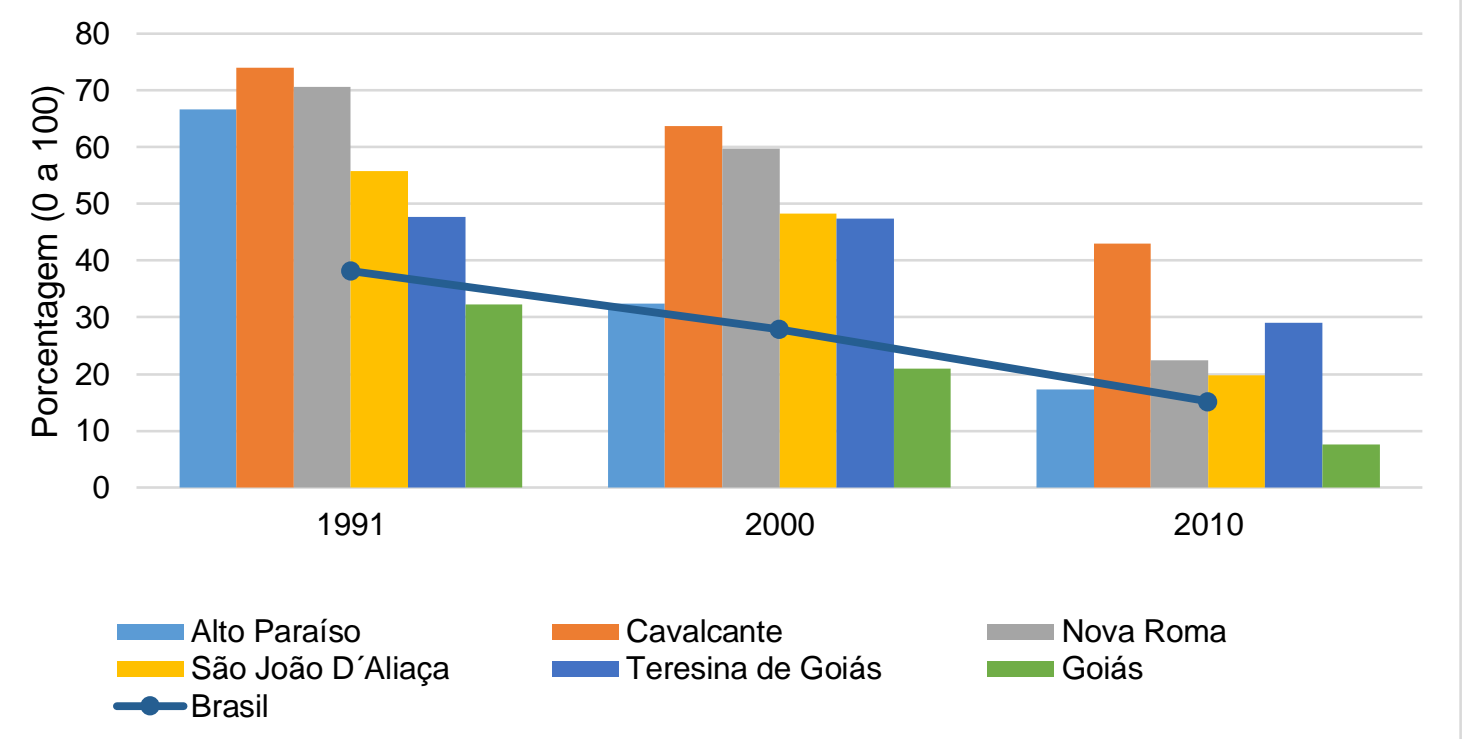

Fonte: Atlas Brasil, PNUD et. al., 2013. Elaborado pelas autoras.

O IDH no ano de 1991 encontrava-se abaixo de 0,550 nos municípios contidos no PNCV, no Estado de Goiás e no Brasil, este valor é classificado como baixo desenvolvimento humano. É interessante observar que ao final do recorte temporal, 
no ano de 2010, todos os entes federados analisados evoluíram para a classificação média e alta, apresentando índices acima de 0,550 e abaixo de 0,799 (Gráfico 4).

Gráfico 4- Índice de Desenvolvimento Humano de Alto Paraíso, Cavalcante, Nova Roma, São João D’Aliança, Teresina de Goiás, Goiás e Brasil - 1991-2010

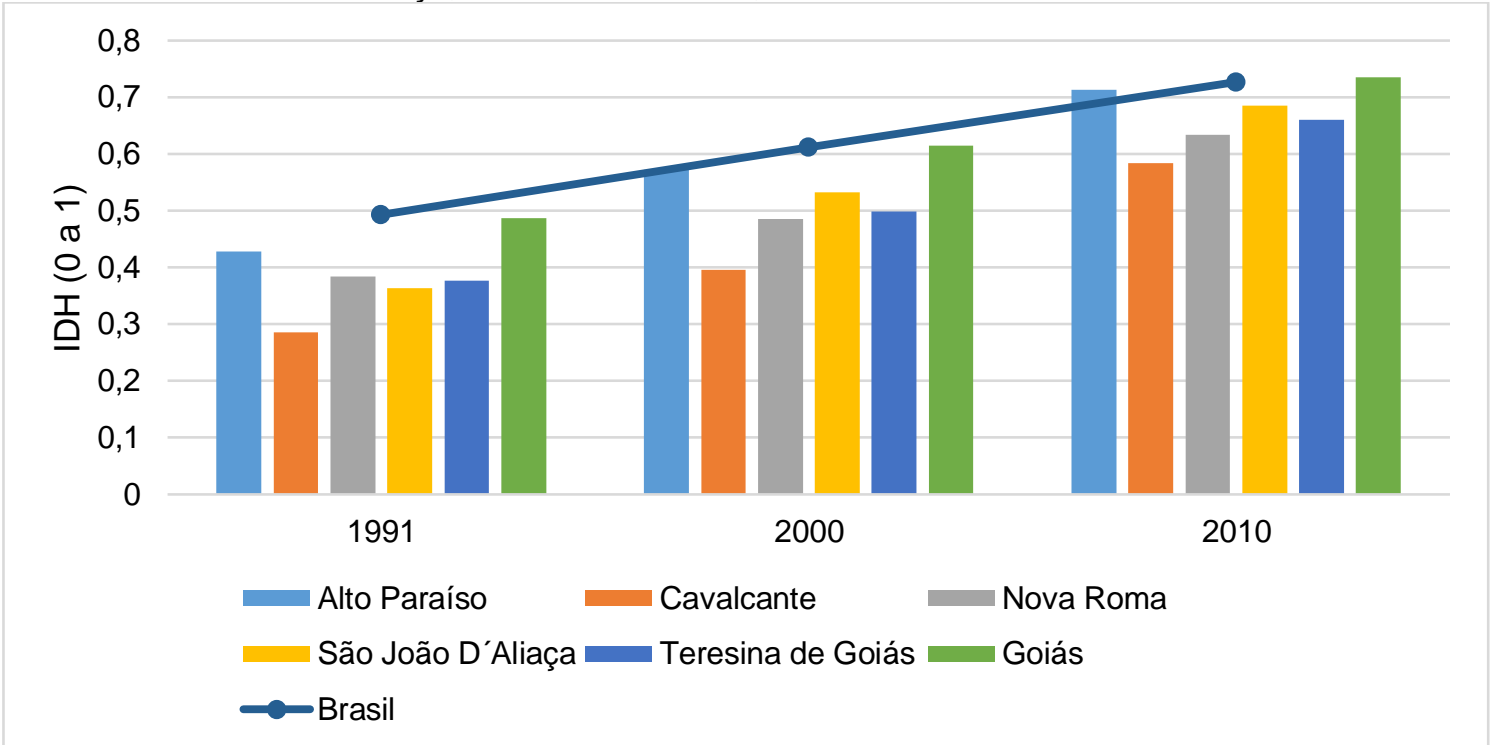

Fonte: Atlas Brasil, PNUD et. al., 2013. Elaborado pelas autoras.

No que se refere ao indicador mortalidade infantil os gráficos nos permitem vislumbrar resultados animadores com a curva significativamente decrescente nos índices de todos os municípios incluídos no PNCV, no Estado de Goiás e no Brasil. Destacamos o grande êxito alcançado por todas as cidades do estudo que chegaram ao ano de 2010 com índice médio de 14,86 mortes de crianças menores de 01 ano a cada mil nascidos vivos, valor inferior ao alcançado pelo Brasil, 16,7 (Gráfico 5).

Gráfico 5- Mortalidade Infantil (quantidade a cada mil nascidos vivos) de Alto Paraíso, Cavalcante, Nova Roma, São João D’Aliança, Teresina de Goiás, Goiás e Brasil - 1991-2010

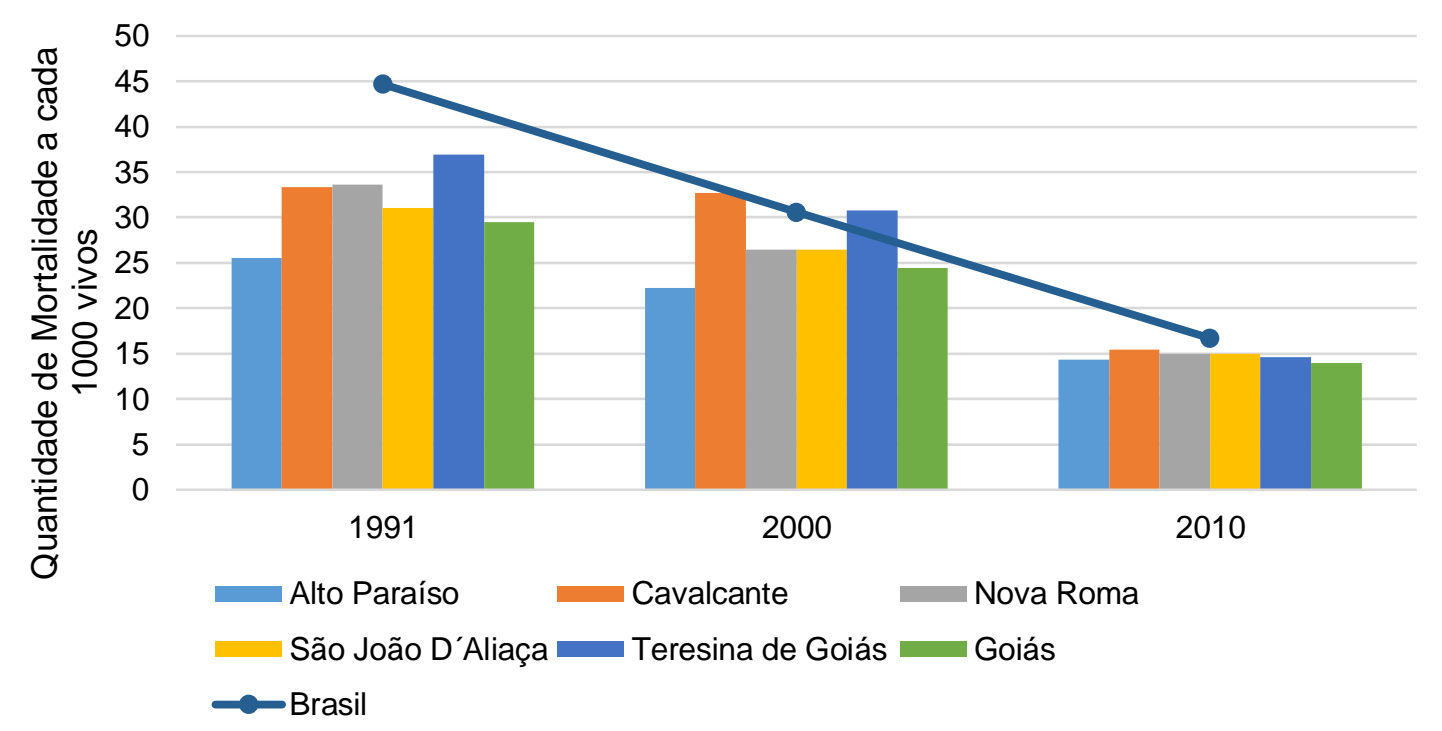

Fonte: Atlas Brasil, PNUD et. al., 2013. Elaborado pelas autoras. 
O Gráfico 6 demonstra um crescimento positivo e linear nos anos de estudo de todos os Entes envolvidos no estudo, ao longo de 19 anos. Interessante observar especialmente o impulso do município de Cavalcante que passou de 4,51 anos de estudo para 8,14 anos no período analisado. Outro fator de destaque foi o estado de Goiás que atingiu média superior ao Brasil durante todo período, mantendo a média de 9,02 anos de estudo (Gráfico 6).

Gráfico 6- Expectativa de Anos de Estudo de Alto Paraíso, Cavalcante, Nova Roma, São João D’Aliança, Teresina de Goiás, Goiás e Brasil - 1991-2010

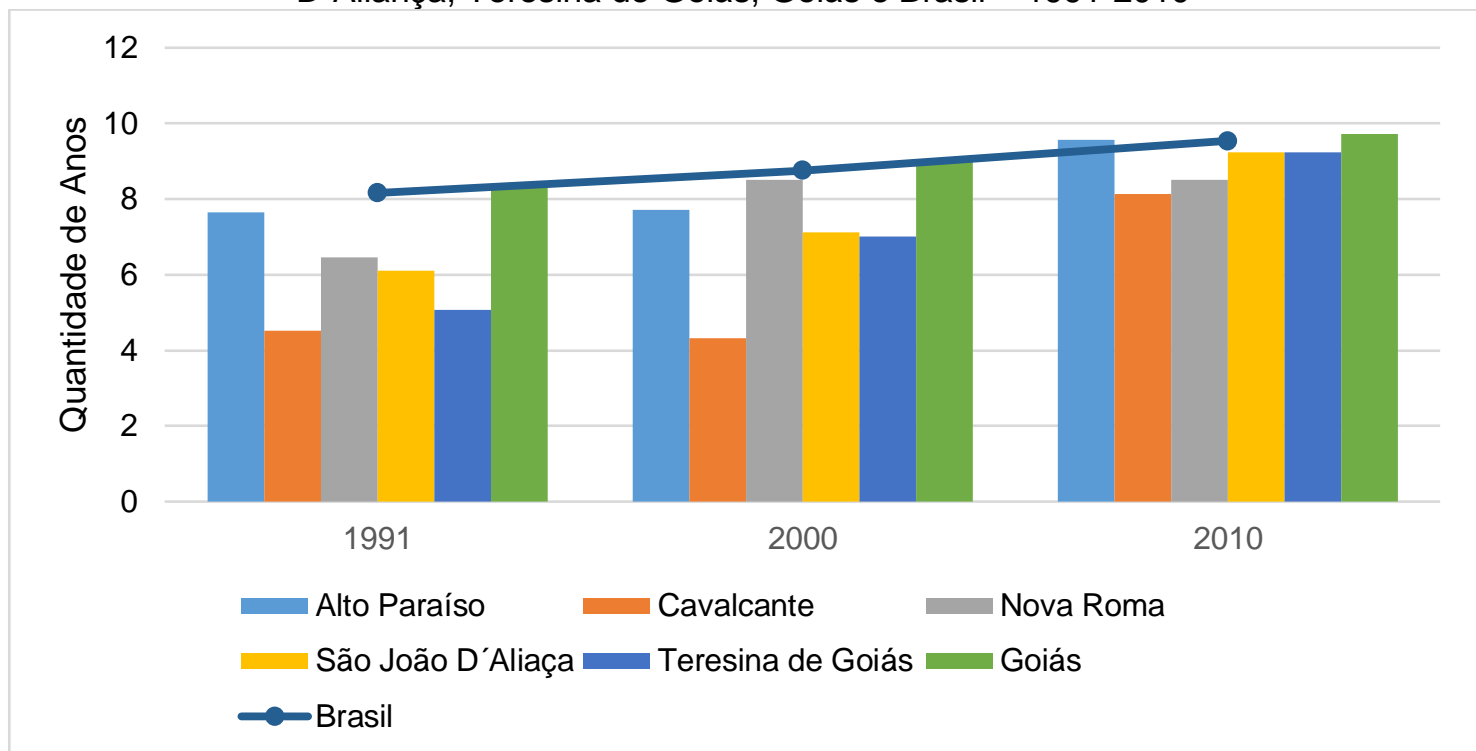

Fonte: Atlas Brasil, PNUD et.al, 2013. Elaborado pela autora.

Para acrescentar maior compreensão da realidade local, utilizou-se índice elaborado pelo Estado de Goiás, que avalia o desempenho de seus municípios, denominado IDM. Foi realizada comparação do IDM relativos às cidades estudadas, em contraponto à cidade que conseguiu o maior (Ouvidor) e o pior (Baliza) desempenho em 2018, pois é possível ver o retrato de desenvolvimento dos municípios estudados após o Censo 2010 (GOIÁS, 2019).

Tabela 1- ÍDM de Alto Paraíso, Cavalcante, Nova Roma, São João D’Aliança, Teresina de Goiás, Ouvidor e Baliza - 2010-2018

\begin{tabular}{lcccc}
\hline Local & $\mathbf{2 0 1 0}$ & $\mathbf{2 0 1 2}$ & $\mathbf{2 0 1 6}$ & $\mathbf{2 0 1 8}$ \\
\hline Alto Paraíso & $5,39^{(225) \underline{5}}$ & $5,58^{(188)}$ & $4,04^{(234)}$ & $4,23^{(224)}$ \\
Cavalcante & $6,27^{(109)}$ & $6,01^{(123)}$ & $4,03^{(236)}$ & $4,10^{(235)}$ \\
Nova Roma & $5,21^{(237)}$ & $5,05^{(240)}$ & $4,33^{(212)}$ & $4,16^{(228)}$ \\
São João d'Aliança & $5,72^{(196)}$ & $5,85^{(147)}$ & $4,02^{(239)}$ & $4,27^{(223)}$ \\
Teresina de Goiás & $5,09^{(244)}$ & $5,17^{(232)}$ & $4,20^{(226)}$ & $3,98^{(241)}$ \\
Ouvidor & $6,49^{(74)}$ & $6,81^{(30)}$ & $5,60^{(9)}$ & $6,14^{(1)}$ \\
Baliza & $5,39^{(226)}$ & $5,27^{(227)}$ & $3,48^{(246)}$ & $3,65^{(246)}$ \\
\hline
\end{tabular}

Fonte: Goiás (2013b); Goiás (2014); Goiás (2016); Goiás (2019). Elaborado pela autora.

\footnotetext{
${ }^{5} \mathrm{O}$ número colocado acima dos índices do IDM corresponde à colocação do município no Ranking estadual, naquele determinado período de tempo. Deve-se ressaltar que no Estado de Goiás existem 246 cidades.
} 
Gráfico 7- ÍDM de Alto Paraíso, Cavalcante, Nova Roma, São João D’Aliança, Teresina de Goiás, Ouvidor e Baliza - 2010-2018

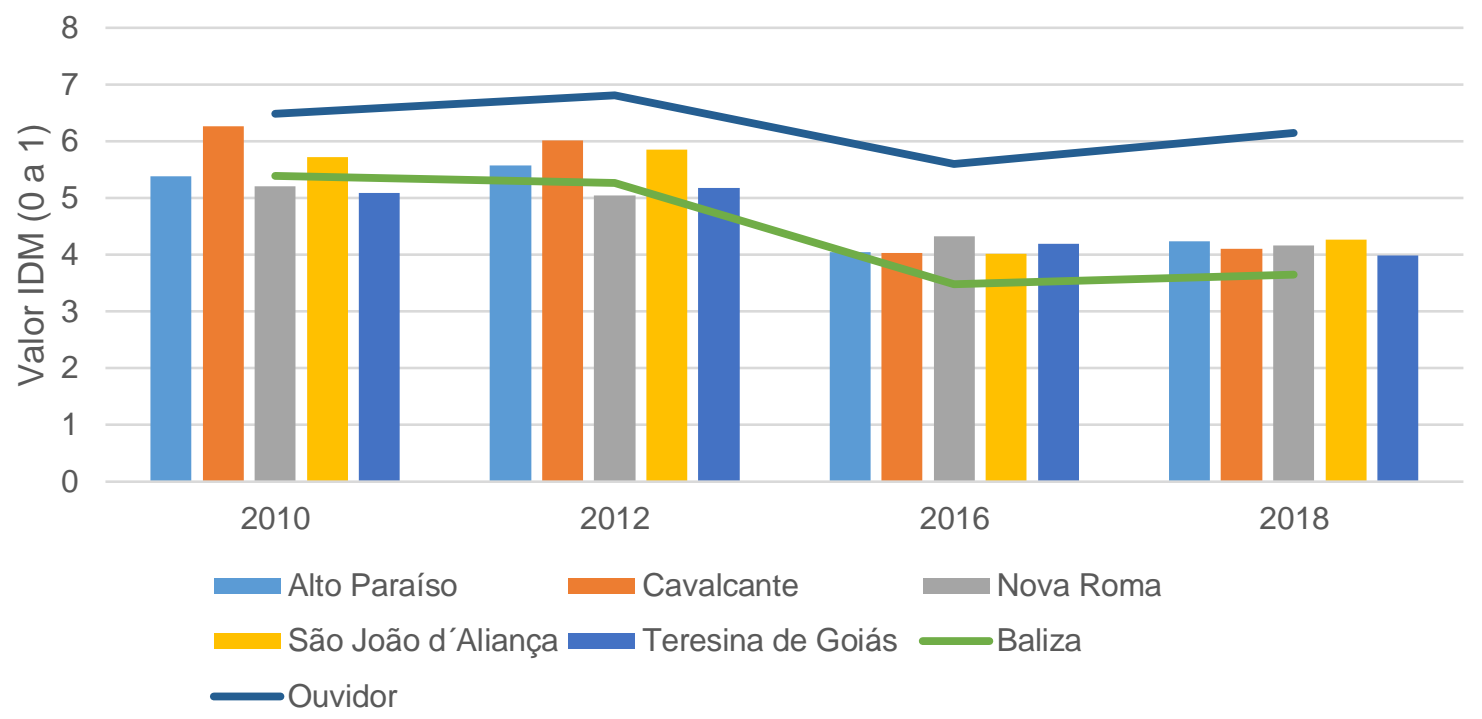

Fonte: Goiás (2013b); Goiás (2014); Goiás ( 2016); Goiás ( 2019). Elaborado pelas autoras.

De acordo com o gráfico 7 , é possível constatar que os municípios onde se localiza o PNCV apresentam índices que se aproximam da cidade que alcançou o menor desempenho em 2018.

Outros dados interessantes trazidos nos relatórios de IDM se referem aos valores brutos que os setores produtivos movimentaram nas cidades analisadas na pesquisa, desde o ano de 2010. Quanto ao setor agropecuário pode-se perceber, no Gráfico 8, um aumento exponencial de crescimento pelas cidades de São João D’Aliança e Teresina de Goiás, enquanto as demais cidades se mantiveram em quantidade relativamente constante. Os dados vão ao encontro do exposto acima, quanto à grande ocupação antrópica da terra no município de São João D’Aliança.

Gráfico 8- Variáveis Originais do Setor Agropecuário de Alto Paraíso, Cavalcante, Nova Roma, São João D’Aliança, Teresina de Goiás, Ouvidor e Baliza - 2010-2018

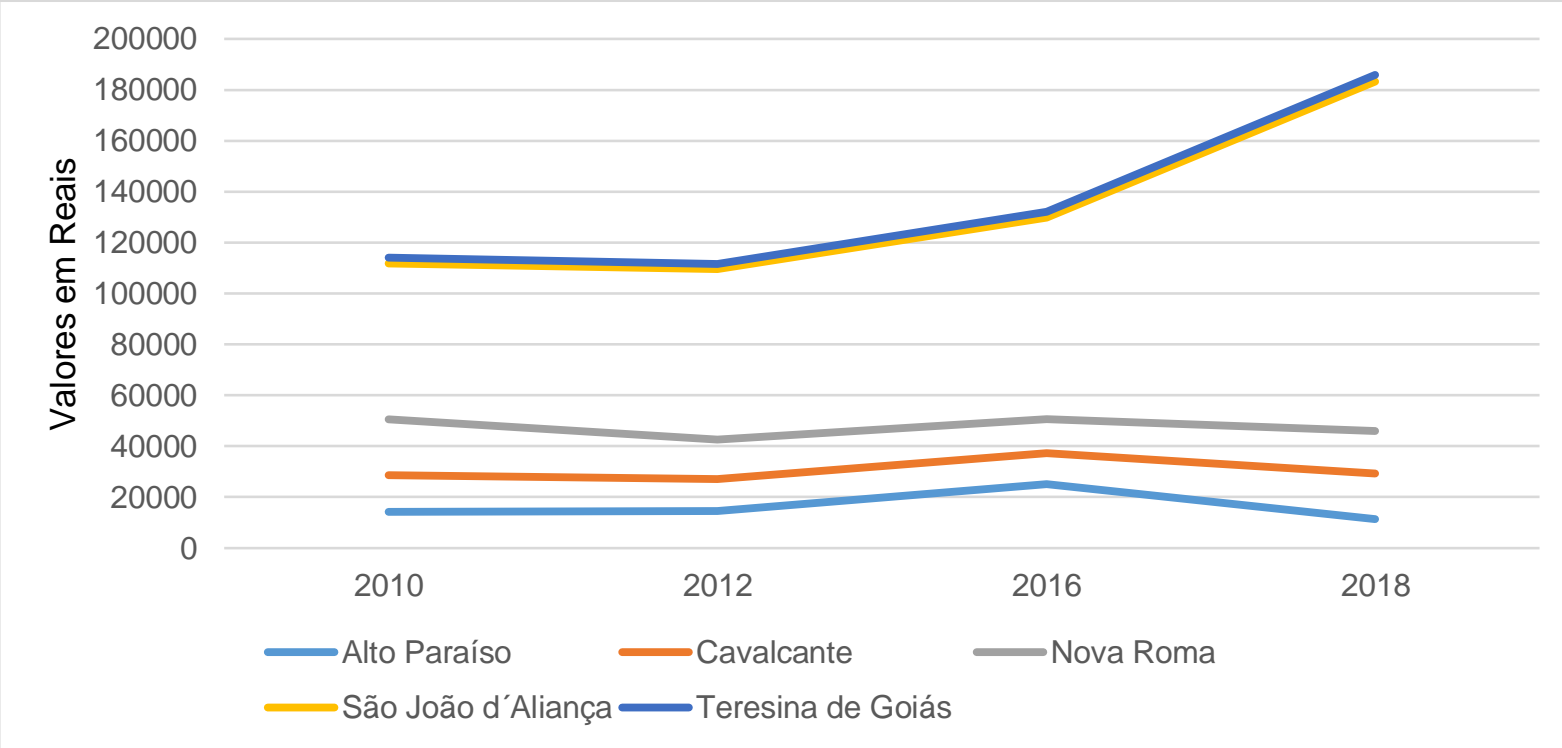

Fonte: Goiás (2013b); Goiás (2014); Goiás (2016); Goiás (2019). Elaborado pelas autoras. 
O gráfico 9 demonstra que Alto Paraíso cresce de forma acelerada no setor de serviços, já Cavalcante sofreu queda vertiginosa de renda produzida pelo setor, enquanto Nova Roma e Teresina de Goiás mantém renda por serviços em valores baixos e praticamente constantes. A exploração econômica do turismo encontra-se nessa categoria, porém, como os dados não foram subdivididos, não é possível afirmar se esta atividade está ou não interferindo de forma determinante na geração de renda das cidades.

Gráfico 9 - Variáveis Originais do Setor de Serviços de Alto Paraíso, Cavalcante, Nova Roma, São João D’Aliança, Teresina de Goiás, Ouvidor e Baliza - 2010-2018

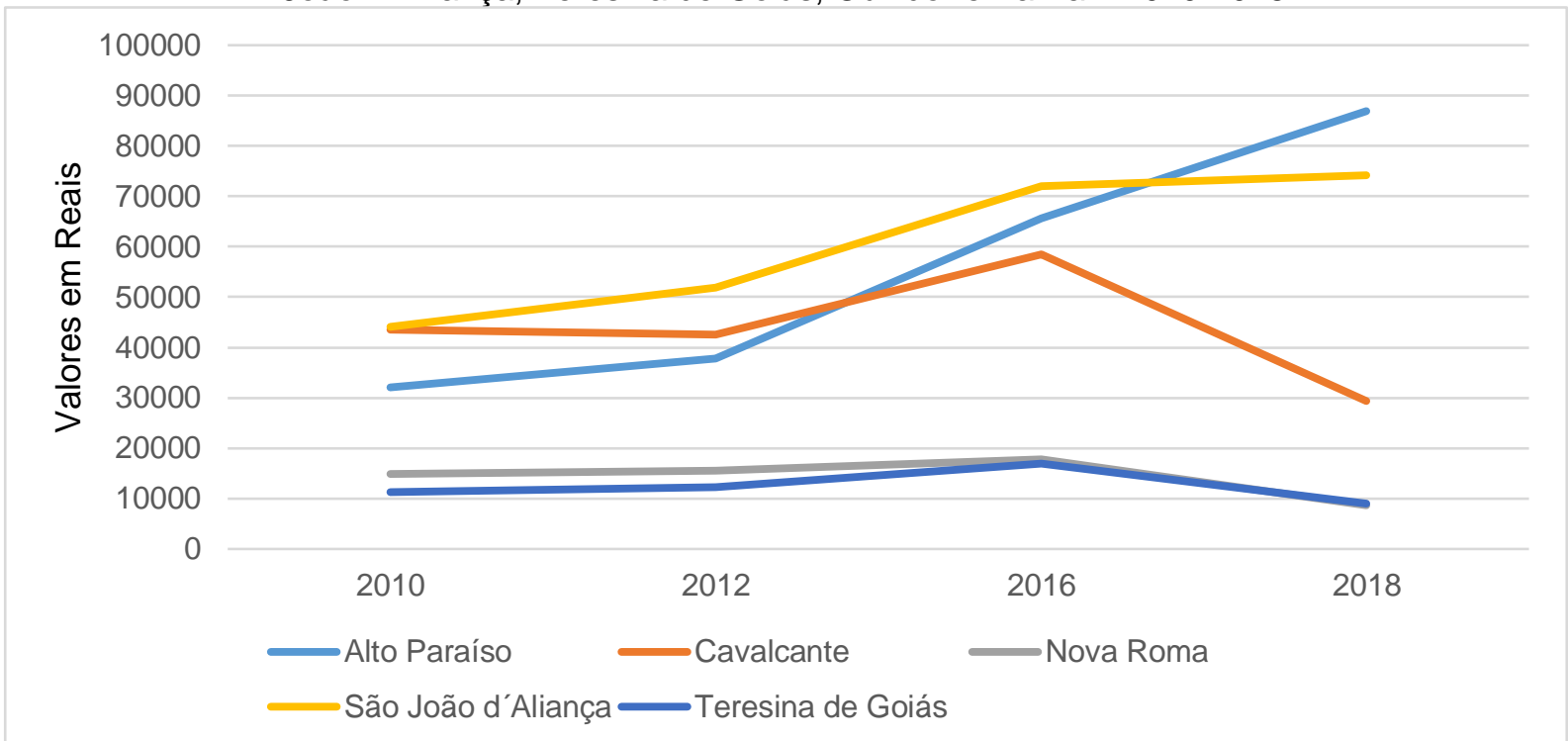

Fonte: Goiás (2013b); Goiás (2014); Goiás (2016); Goiás ( 2019). Elaborado pelas autoras.

No Gráfico 10, percebe-se que o setor secundário dos municípios estudados, com exceção de Cavalcante, é insignificante na geração de riqueza para a região.

Gráfico 10 - Variáveis Originais do Setor Industrial de Alto Paraíso, Cavalcante, Nova Roma, São João D’Aliança, Teresina de Goiás, Ouvidor e Baliza - 2010-2018

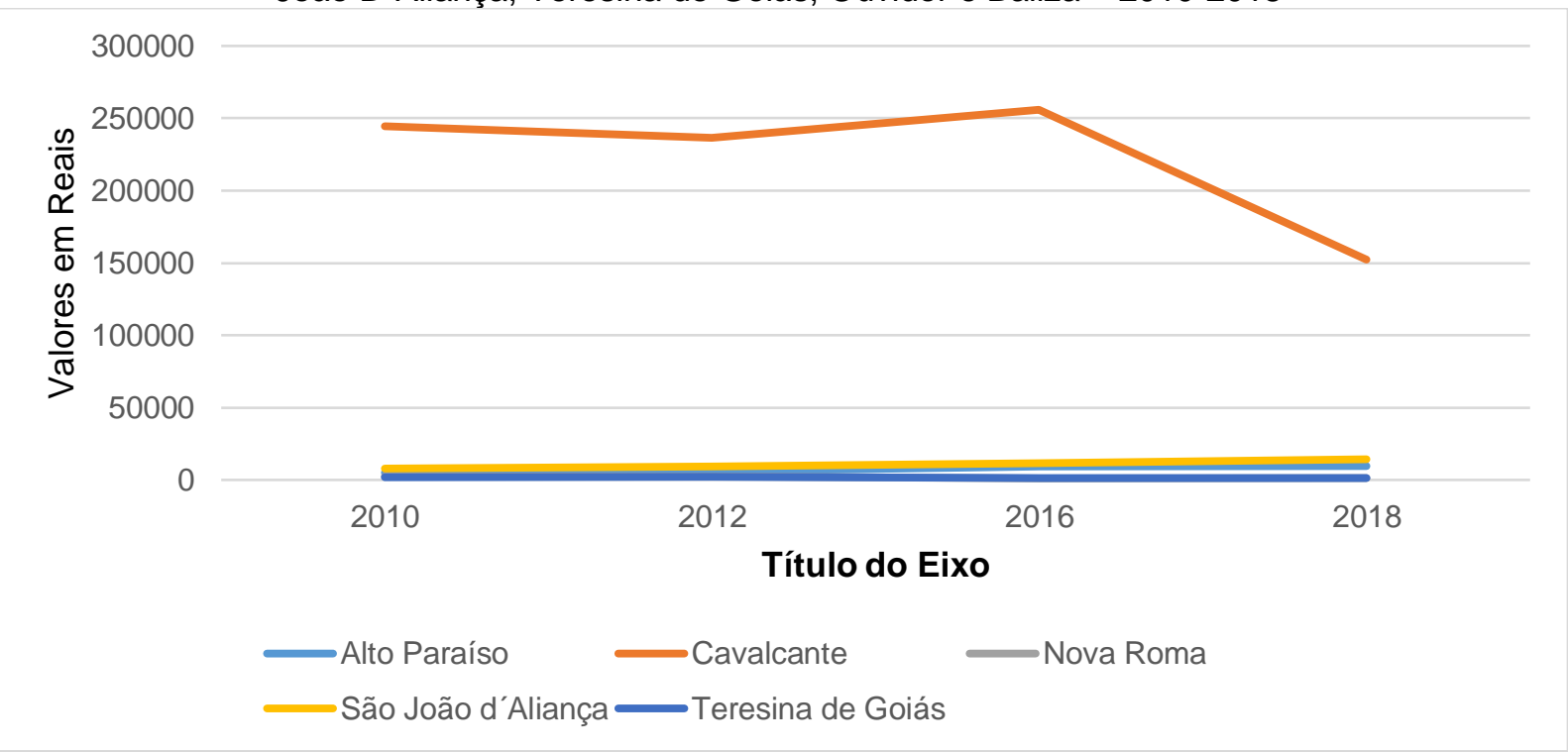

Fonte: Goiás (2013b); Goiás (2014); Goiás ( 2016); Goiás ( 2019). Elaborado pelas autoras. 
A discussão dos resultados permitiu verificar que as cidades que compõem o PNCV são pequenas, com PIB baixos, pouco desenvolvidas e socialmente vulneráveis. Assim, as ações governamentais voltadas à conservação ambiental também devem planejar meios para que a riqueza natural consiga gerar renda e prosperidade regional.

\section{CONSIDERAÇÕES FINAIS}

Os dados analisados não permitiram concluir sobre os impactos econômicos que a constituição da unidade de conservação de proteção integral gerou sobre as cidades cingidas pelo PNCV.

Isso mostra que se trata de uma região com a porcentagem de pobres acima da média nacional e do Estado de Goiás e com IDM baixo, próximos aos piores do estado. Não é possível afirmar que tais características sejam decorrência das leis ambientais que determinam a restrição nos meios de exploração da terra ou decorrência dos aspectos estruturais do nordeste goiano.

Os gráficos demonstram ainda, que mesmo contando com índices insatisfatórios, quando comparados com os valores estaduais ou nacionais, existiu desenvolvimento da região, com aumento médio de $80,12 \%$ no IDHM e queda média de $57,55 \%$ na porcentagem de pobres e de 53,08\% da mortalidade infantil. Também não é possível afirmar se tais avanços foram ocasionados por um modelo de desenvolvimento econômico sustentável que as riquezas ambientais podem proporcionar.

Ressalta-se que além da grande extensão de terra, o PNCV possui diversas cachoeiras com potencial hidrelétrico e importantes minas de fosfato, nióbio, manganês, ouro e urânio. Assim, existem interesses econômicos para que esta área de Preservação seja explorada mais intensamente. Observa-se, no entanto, que pesquisa realizada com a população desta região, em decorrência da elaboração do Plano de Manejo dessa UC, evidencia que os residentes entendem que a preservação ambiental seja o caminho a ser perseguido ao invés da exploração mineral ou instalação de hidrelétricas.

Apesar dos entraves existentes contra as demarcações de terras públicas o PNCV encontra-se amparado legalmente e ocupa área de 240.611 hectares. Antropologicamente sua riqueza é inestimável por proteger populações extremamente vulneráveis como as comunidades quilombolas e abrigar as aldeias dos índios AvaCanoeiros.

Esse estudo não pretendeu esgotar o assunto e sugere-se que mais pesquisas sobre o tema e acompanhamento das cidades onde se localiza o PNCV precisam ocorrer. Se com o tempo for demonstrado que comunidades conseguem se desenvolver econômica e socialmente em local que goza de forte proteção ambiental, existirá a confirmação da premissa de que não é somente a degradação dos recursos naturais que gera o progresso.

O fomento à exploração de atividades com baixo impacto ambiental como o ecoturismo, turismo histórico-cultural, artesanato, promoção de eventos e produção de agricultura orgânica são alternativas para enfrentar problemas sociais e econômicos detectados no estudo. Tais atividades, se bem orientadas e gerenciadas, têm capacidade de preservar essa importante UC; possibilitam criação de emprego e renda para os citadinos; trazem desenvolvimento e investimento para as cidades; preservam as comunidades e a cultura quilombola da região; e são capazes de 
propagar a beleza e a importância de preservação dessa região a nível nacional e internacional.

\section{REFERÊNCIAS}

AMATO, Ciro et al. Sviluppare il potenziale delle aree protette alpine: I report della rete SAPA - Sistema delle aree protette italiane. Itália, 2017. Disponível em: http://www.areeprotette-sapa.it/pubblicazioni/. Acesso em: 14 abr. 2019.

BASSI, Marco. Nuove frontiere nella conservazione della biodiversità: patrimoni di comunità e assetti fondiari collettivi. Itália, 2016. Disponível em: https://www.researchgate.net/publication/323074841_Nuove_frontiere_nella_conserv azione_della_biodiversita_Patrimoni_di_comunita_e_assetti_fondiari_collettivi.

Acesso em: 14 abr. 2019.

BRASIL. Ministério do Meio Ambiente. O bioma cerrado. Disponível em: http://www.mma.gov.br/biomas/cerrado.html. Acesso em: 8 set. 2018.

BRASIL. Ministério do Meio Ambiente. Constituição da República Federativa do Brasil. Brasília, DF. 1988. Disponível em: http://www.planalto.gov.br/ccivil 03/constituicao/ constituicaocompilado. htm. Acesso em: 8 set. 2018.

BRASIL. Ministério do Meio Ambiente Decreto de 05 de Junho de 2017. Amplia o parque nacional chapada dos veadeiros. Brasília, DF, jun. 2017. Disponível em: http://www2.camara.leg.br/legin/fed/ decret_sn/2017/decreto-57624-5-junho-2017785018-publicacaooriginal-152959-pe.html. Acesso em: 11 set. 2018.

BRASIL. Ministério do Meio Ambiente. Lei 9.985 de 18 de julho de 2000. Institui o sistema nacional de unidades de conservação da natureza. Brasília, DF, jul. 2000. Disponível em: http://www.planalto.gov.br/ccivil_03/leis/L9985.htm. Acesso em: 8 set. 2018.

CAVALCANTE. A cidade. Disponível em: https://www.cavalcante.go.gov.br/\#cidade_link. Acesso em: 12 set. 2018.

CONHEÇA Teresina de Goiás o mais novo destino da chapada dos veadeiros. Curta mais. Goiânia, 2018. Disponível em: http://www.curtamais.com.br/goiania/conhecateresina-de-goias-o-mais-novo-destino-da-chapada-dos-veadeiros. Acesso em: 12 set. 2018.

GOIÁS. Agência Estadual de Turismo. Plano de Desenvolvimento Integrado do Turismo Sustentável (PDITS) - Polo chapada dos veadeiros. 2013a. Disponível em: http://www.goiasturismo.go.gov.br/downloads/prodetur/. Acesso em: 12 set. 2018.

GOIÁS. Agência Estadual de Turismo. Instituto Mauro Borges de Estatísticas e Estudos Econômicos. Índice de Desempenho dos Municípios Goianos: IDM 2010. Goiânia, 2013b. Disponível em: http://www.imb.go.gov.br/index.php?option=com_content\&view=category\&layout=blo g\&id=31\&Itemid=177. Acesso em: 2 jun. 2019. 
GOIÁS. Agência Estadual de Turismo Instituto Mauro Borges de Estatísticas e Estudos Econômicos. Índice de Desempenho dos Municípios Goianos: IDM 2012. Goiânia, 2014. Disponível em: <http://www.imb.go.gov.br/index.php?option=com_content\&view=category\&layout=bl og\&id=31\&ltemid=177>. Acesso em: 2 jun. 2019.

GOIÁS. Agência Estadual de Turismo. Instituto Mauro Borges de Estatísticas e Estudos Econômicos. Índice de Desempenho dos Municípios Goianos: IDM 2016. Goiânia, 2016. Disponível em: http://www.imb.go.gov.br/index.php?option=com_content\&view=category\&layout=blo g\&id=31\&ltemid=177. Acesso em: 2 jun. 2019.

GOIÁS. Agência Estadual de Turismo. Instituto Mauro Borges de Estatísticas e Estudos Econômicos. Índice de Desempenho dos Municípios Goianos: IDM 2018. Goiânia, 2019. Disponível em: http://www.imb.go.gov.br/index.php?option=com_content\&view=category\&layout=blo g\&id=31\&ltemid=177. Acesso em: 2 jun. 2019.

IBGE. Instituto Brasileiro de Geografia e Estatística. Institucional. Brasil, 2017. Disponível em: http://www.ibge.gov.br. Acesso em: 11 set. de 2018.

ICM-BIO. Instituto Chico Mendes de Preservação da Biodiversidade. Plano de manejo parque nacional chapada dos veadeiros. Brasília, 2009. Disponível em: http://www.icmbio.gov.br/portal/unidadesdeconservacao/biomas-

brasileiros/cerrado/unidades-de-conservacao-cerrado/2081-parna-da-chapada-dos-

veadeiros. Acesso em: 2 jun. de 2019.

LIMA, Priscylla Cristina Alves de. As RPPNs da Chapada dos Veadeiros: disposições, motivações e práticas sociais. 2013. 160 f. Dissertação (Mestrado em Desenvolvimento Sustentável)- Centro de Desenvolvimento Sustentável, Universidade de Brasília, Brasília, 2013. Disponível em: http://repositorio.unb.br/bitstream/10482/13884/1/2013_PriscyllaCristinaAlvesdeLima .pdf. Acesso em: 17 set. 2018.

NOVA ROMA. História. Nova Roma, 2018. Disponível em: http://www.novaroma.go.gov.br/pagina/144-historia. Acesso em: 12 set. 2018.

OLIVEIRA, Fabiano Melo Gonçalves de. Direito Ambiental. 2. ed. Rio de Janeiro: Forense; São Paulo: Método, 2017.

PNUD. Programa das Nações Unidas para o Desenvolvimento; IPEA. Instituto de Pesquisa Econômica e Aplicada; Fundação João Pinheiro. Atlas de desenvolvimento humano do Brasil de 2013. 2013. Disponível em: http://www.atlasbrasil.org.br/2013/pt/home/. Acesso em: 30 mai. 2019.

SÃO JOÃO D’ALIANÇA. História do Município. 2018. Disponível em: http://www.saojoaodalianca.go.gov.br/pagina/128-historia-do-municipio. Acesso em: 12 set. 2018. 
SILVA, Mariana Santos da, et al. 30 anos de dinâmica espaço-temporal (1984-2015) da região de influência do Parque Nacional Chapada dos Veadeiros - Goiás. Revue franco-brésilene de géographie=Revista franco-brasilera de geografia, n. 35, 2018. Disponível em: https://journals.openedition.org/confins/14851. Acesso em: 5 mar. 2019.

UNESCO. Organização das Nações Unidas para a Educação, a Ciência e a Cultura. Representação da Unesco no Brasil. Patrimônio natural no Brasil: áreas de proteção no cerrado. Brasil, 2017. Disponível em: http://www.unesco.org/new/pt/ brasilia/ natural-sciences/environment/natural-heritage. Acesso em: 12 set. 2018.

WOLFFENBÜTTEL, Andréa. O que é? Índice de Gini. Revista Desafios do Desenvolvimento, Brasília, v.1, n.4, p.01, nov. 2004. IPEA. 